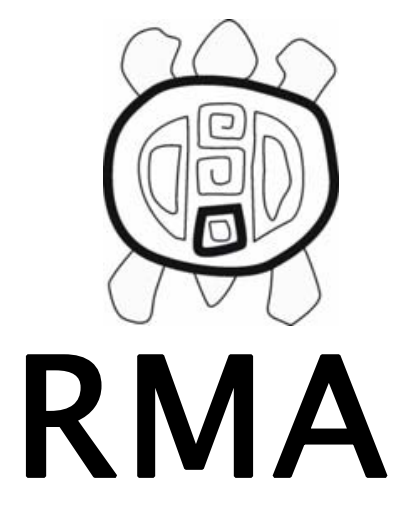

DOSSIER:

\title{
Intelectuales y Editores
}

El intelectual abre ideas, el editor las cierra. El escritor produce textos, el editor impresos. El intelectual escribe pero es el editor quien publica. No por nada, afirman algunos psicólogos, el pensamiento culmina con su publicación. Entre el escritor y el editor se moviliza una energía simbólica y social sublimada bajo las líneas impresas que llegan al lector. Ese entre-lugar de producción de sentidos, de cosmologías, de sociedad que marcó la formación de gran parte de las culturas desde la aparición de la expresión gráfica de las ideas, permanece como un problema esquivo para la investigación, al menos para la antropología practicada en estas latitudes. Parece una cuestión obturada por el dominante acúmulo de historias de las ideas, de la literatura, del pensamiento que reactualizan la oposición entre espíritu y materia, estética y sociedad, texto y contexto. Evidencia de ello es la clausura sufrida por la sociología de la literatura, una sub-disciplina tan incómoda para los guardianes del aura del genio literario nacional.

Este dossier busca iluminar esa relación con la certeza de que modela uno de los terrenos más fértiles para repensar el legado de la historia de la cultura en occidente y para generar un basto programa de problemas de investigación escasamente explorados por las ciencias sociales y humanas en América Latina, y aplicables al estudio de toda cultura, con o sin escritura.

El problema parece inobjetable para la historia cultural. De hecho en este dominio dio lugar a uno de los debates más incisivos para su renovación. Basta observar el justo reconocimiento a dos autores como Roger Chartier o Robert Darnton. Desde los años 80 se ha conformado un campo internacional de estudios sobre intelectuales, editores, lectores, con sus revistas, congresos, asociaciones. Algunos nudos de ese espacio se desarrollan en universidades como Sherbrooke en Québec o Versailles SaintQuentin-en-Yvelines, en Francia, que alojan centros documentales, cátedras específicas, cursos especializados permanentes. El Programa de Historia Intelectual de la Universidad de Quilmas, con su «ejemplar» revista Prismas, representa un lugar que en Argentina sintoniza con ese campo de investigaciones internacional.

Para la antropología social, sin embargo, ese problema exigiría una compleja argumentación. A pesar de las transformaciones del objeto de esa disciplina que llevaron a la celebre afirmación de Clifford Geertz «ahora somos todos nativos», problema sintetizado con sutileza por Mariza Peirano al modelizar las variaciones entre relaciones de alteridad máxima y mínima (antropólogos estudiando antropólogos y el ya trillado problema de la reflexividad) y tematizado por Adrián Gorelik en su estudio del debate Redfield - Lewis, el lugar de la escritura en las culturas estudiadas por los antropólogos ha sido fragmentariamente abarcado. La referencia más popular al ingreso de la escritura como tópico para la reflexión disciplinar pasa por Geertz y El antropólogo como autor de 1983. La antropología post-moderna explotó y esterilizó ese filón con el tema recursivo de la escritura etnográfica, tomada como una cuestión estética de aparentes consecuencias políticas.

Sin embargo, Jack Goody, en Cambridge, desde finales de los años 50 comenzó a pensar las implicaciones de la cultura escrita sobre los procesos cognitivos en culturas con o sin escritura. En La domesticación del pensamiento salvaje (1977) compuso una de las críticas más virtuosas al estructuralismo: la paradoja neolítica planteada en El Pensamiento Salvaje (1962), le permitía a Claude Lévi-Strauss oponer y explicar mutuamente la composición del pensamiento mágico - mítico y del pensamiento lógico de la ciencia moderna, como dos formas alternativas que produce el espíritu humano para ordenar, clasificar, conocer, concebir un mundo inteligible. El extraordinario antropólogo francés afirmaba que mentes a la altura de Einstein o Platón debieron estar por detrás de la domesticación de los alimentos y dejaba en suspenso la razón por la cual entre el neolítico y el renacimiento los descubrimientos habían casi cesado. Se trataba de una paradoja bajo una perspectiva para la cual la historia de la constitución del pensamiento científico no contaba. Bastaba con modelizar, en el plano 
de la sincronía, la relación inversa entre un pensar que parte de acontecimientos heteróclitos ordenados en función de estructuras pre-determinadas o de un pensar que parte de proyectos racionalizados que buscan abrir las estructuras hacia nuevos acontecimientos. Goody subrayó el etnocentrismo de esa Gran Divisoria de la teoría al mostrar que pivoteaba sobre binarismos propios a la organización del pensamiento occidental: frío / caliente; mito / historia; bricoleur / ingeniero, etc. Para Goody, LéviStrauss descartó el estudio del pasaje entre esas dos formas de estructuración del pensamiento y comprobó que la escritura, especialmente el desarrollo del alfabeto fonético desarrollado en la Grecia clásica, constituía un tema crucial: el control sobre la escritura repercutió en la legitimación de sociedades estamentales; permitió la concepción de religiones monoteístas y universalistas; produjo efectos directos e indirectos sobre todo tipo de formaciones sociales y culturales en extensas regiones, hasta tornarse globales tras la conquista del Nuevo Mundo por los europeos. Además de un arte de pensar, la ciencia moderna era el producto de determinadas instituciones y estructuras comunicativas, como la palabra impresa. Los mitos que Goody registraba entre los LoWiili y los Lodogon del norte de Ganha en los años 50, no guardaban relación con las formas típico-ideales planteadas por Lévi-Strauss. Esos mitos, especialmente el recitado dramatizado del Bagre, no eran comprensibles sin los efectos del Islam, sin el problema del sujeto al que abría el acto de premiar a quien mejor los recitaba y las «infinitas» variaciones que, sobre una estructura de significación general (la ambivalencia de un Dios que ha abandonado a una sociedad plagada por males), registró en dos momentos de observación: 1954 y 1970. La variación, la ambivalencia, la acción particular, el cambio no podían ser trituradas a favor de un problema formal de tipo lingüístico, a un silogismo filosófico. Goody asumió ese desafío, incorporó definitivamente la historia y el individuo para comprender la acción creativa sobre la cultura hasta permitirse formular la pregunta: «ilntelectuales en sociedades sin escritura?» Oralidad y escritura se presentan para este autor como una relación insoslayable para comprender la transmisión de la cultura, la dialéctica entre el pensamiento y sus múltiples inscripciones materiales. Podríamos decir que Goody terminó de escribir un capítulo decisivo para «una ciencia de lo concreto». Basta observar lo poco que es leído Jack Goody en nuestro país para preguntarse sobre las razones de la frontera que lo separa y sobre las virtudes de lo que abriría el franqueo de ese límite.

Este dossier presenta cuatro aportes para abrir diálogos y espacios de investigación innovadores. Son producto de un fecundo diálogo entre dos colectivos de investigación: el mencionado Programa de Historia Intelectual, dirigido por Carlos Altamirano en la UNQ, y el Programa Cultura Escrita, Mundo Impreso y Campo Intelectual de nuestro Museo de Antropología. Éste, de reciente formación, debe a aquél un modelo no sólo de producción de conocimiento, sino también ético. En ese diálogo, pleno de rigor y afecto, la interdisciplina no es un decreto, se enfrenta y genera un espacio de renovación permanente que aquí se expone como un capítulo más para sumar y construir. Todos los textos son resultados de diálogos de larga data, de intercambios y críticas cruzadas: el de Adrián Gorelik se apoya en la historia intelectual e ilumina la función de la crítica académica y cultural para la renovación de las disciplinas sociales, como la antropología y el urbanismo. No se contenta con analizar ideas, sino en trazar la historia de las argumentaciones, de su circulación, apropiaciones y efectos en dimensiones sociales como el plano institucional. Los antropólogos no solamente podemos ser nativos para otros antropólogos sino también para otros especialistas. Ser mirados desde afuera posibilita pensar los riesgos de la endogamia disciplinar y ampliar así los horizontes de lo pensable e investigable. Recuerdo la demanda de Adrián a inicios de siglo para ampliar las lecturas sobre el debate Redfield y Lewis y para trasmitirle una opinión sobre el lugar de esos autores en los debates de la antropología argentina. Recordé la cuasi-condena que dominaba en nuestro espacio académico sobre esos autores, triturados en las simplistas clasificaciones de manual sobre la historia de las «corrientes» antropológicas: funcionalistas! La mirada distanciada, crítica, desprejuiciada sobre aquellos investigadores situados en espacios y tiempos concretos, conduce a un cuestionamiento de los criterios del juicio sobre sus obras, sus espacios de trabajo y el posible impacto de la producción intelectual de los antropólogos sobre la imaginación de las culturas y las sociedades. Los prejuicios (temores ante peligros que pondrían en riesgo el orden del discurso disciplinar, podríamos decir con Foucault) que esconden los taxones de la historia de la antropología, inhiben pensar la incidencia de ese y tantos otros debates en la reformulación de tópicos significativos en la historia de otras disciplinas y realidades culturales. Cabe a los antropólogos ampliar el espectro de problemas de investigación, actitud que implica, al mismo tiempo, enfrentar las limitaciones etnocéntricas de su tradición. 